\title{
Publisher Correction: Oncolytic viruses as engineering platforms for combination immunotherapy
}

Kwame Twumasi-Boateng, Jessica L. Pettigrew, Y. Y. Eunice Kwok, John C. Bell(D) and Brad H. Nelson

Nature Reviews Cancer (2018) https://doi.org/10.1038/s41568-018-0009-4

Published online 25 April 2018

In the online html version of this article, the affiliations for Jessica L. Pettigrew and John C. Bell were not correct. Jessica L. Pettigrew is at the Department of Medicine, University of British Columbia, Vancouver, British Columbia, Canada and John C. Bell is at the Center for Innovative Cancer Therapeutics, Ottawa Hospital Research Institute, Ottawa, Ontario, Canada. This is correct in the print and PDF versions of the article and has been corrected in the html version.

https://doi.org/10.1038/s41568-018-0019-2 I Published online 4 May 2018

\section{Author Correction: Inflammatory breast cancer biology: the tumour microenvironment is key}

Bora Lim (D), Wendy A. Woodward, Xiaoping Wang, James M. Reuben and Naoto T. Ueno

Nature Reviews Cancer https://doi.org/10.1038/s41568-018-0010-y (2018) Published online 27 April 2018

The originally published article contained an error in Table 1, in which two neoadjuvant clinical trials (NCT02876107 and NCT03101748) were not included. This omission has been corrected in the online and print versions of the manuscript through the addition of these two trials and their relevant details (agents, cohort details, targeted biology, main targeted pathway or characteristic and phase) to Table 1.

https://doi.org/10.1038/s41568-018-0022-7 I Published online 10 May 2018

\section{Author Correction: A causal mechanism for childhood acute lymphoblastic leukaemia}

\section{Mel Greaves}

Nature Reviews Cancer (2018) https://doi.org/10.1038/s41568-018-0015-6

Published online 21 May 2018

The article as originally published cited the incorrect paper as reference 123 . The correct reference is Kroll, M. E., Draper, G. J., Stiller, C. A. \& Murphy, M. F. G. Childhood leukemia incidence in Britain, 1974-2000: time trends and possible relation to influenza epidemics. J. Natl Cancer Inst. 98, 417-420 (2006). This has been corrected in the online and print versions of the article.

https://doi.org/10.1038/s41568-018-0029-0 I Published online 30 May 2018 